\title{
Assessment of Improved Cookstoves and Its Implication on Energy Saving and Environmental Protection in Kisumu County, Kenya
}

\author{
Benard Oula Muok ${ }^{1, *}$, Calleb Ochia Olweny ${ }^{2}$ \\ ${ }^{1}$ Directorate of Research, Innovation and Partnerships, Jaramogi Oginga Odinga University of Science and Technology, Bondo, Kenya \\ ${ }^{2}$ Department of Plant, Animal and Food Science, Jaramogi Oginga Odinga University of Science and Technology, Bondo, Kenya
}

Email address:

bmuok@yahoo.com (B. O. Muok), callebolweny@yahoo.com (C. O. Olweny)

${ }^{*}$ Corresponding author

To cite this article:

Benard Oula Muok, Calleb Ochia Olweny. Assessment of Improved Cookstoves and Its Implication on Energy Saving and Environmental Protection in Kisumu County, Kenya. International Journal of Sustainable and Green Energy. Vol. 9, No. 2, 2020, pp. 38-44. doi: $10.11648 /$ j.ijrse.20200902.13

Received: May 7, 2020; Accepted: May 25, 2020; Published: June 3, 2020

\begin{abstract}
In this paper, we examine the efficiency of different improved cookstoves (ICS) in the Kenya market to understand their impact on household energy saving and deforestation. Similar to many other countries in the global south, especially in sub-Sahara Africa (SSA), in Kenya traditional cooking methods such as the three stone cookstove (TSC) are still dominant, especially in the rural households. These types of stoves have very low efficiency levels, and therefore require large amounts of fuelwood with substantial negative impact on the environment and human health. Despite the three decades of improved cookstove development and promotion in Kenya, the penetration remains low especially in the rural areas where it is estimated that over $90 \%$ are still relying on the traditional TSC for cooking. Lack of data on stoves testing has been proposed as one of the critical bottlenecks to adoption of improved cookstove. The study aims to address this gap by providing stove-testing data on some of the stoves currently in the market. The study was conducted in all the 7 sub-counties of Kisumu County. It adopted a mixed method approach, which included quantitative and qualitative methods. Qualitative studies included literature review, key informant interviews (KIIs) and focused group discussion while quantitative studies included household interviews and stove performance. A total of 400 households were interviewed. The data obtained shows that firewood and charcoal are the most dominant fuel used for cooking as recorded in $74 \%$ and $67 \%$ of the interviewed households, respectively. Further, majority of the respondents believed that the tree cover in their areas is diminishing mainly due to the destruction of woodland for fuelwood. Three stoves were used for this study, which included the traditional three stone cookstove (TSC), Integrated Domestic Energy Unit (IDEU micro-gasifier stove) and Kuni mbili stove. Both IDEU and Kuni mbili performed better than the traditional three stone cookstove sin all the parameters such Kitchen test and controlled cooking test as well as emission reduction. IDEU was superior to all the stoves tested. The study has provided valuable data on kitchen performance which will provide useful insight on potential energy saving and forest. Besides, the study also pointed out at the weaknesses of some of the improved stoves in the market and need for further design adjustment to improve efficiency.
\end{abstract}

Keywords: Clean Cookstoves, Energy Access, Forest Degradation, Fuel Saving

\section{Introduction}

This study examines the efficiency of different improved cookstoves (ICS) in the Kenya market and elucidate their impact on household energy saving and deforestation with the overall goal of supporting the on-going global and national effort to promote transition to clean cooking solutions. As the developed world moves into a future characterized by new clean energy sources and driven by technology and innovation, millions of Africans are still reliant on traditional biomass using the tree stone cookstoves and charcoal for cooking. At the same time, kerosene lamps, wood and candles dominate household lighting. The continent is home to almost 600 million people who currently have no electricity access and 
900 million without clean cooking options. It is estimated that $70 \%$ of households in Kenya still use woodstove either as their primary or secondary cookstove, with prevalence of $92 \%$ in rural areas. Further, these households use woodfuel (fuelwood or charcoal) as their primary fuel [1].

Energy demand is a crucial driver of rampant deforestation and roadside sales of charcoal and is providing livelihoods to thousands of people. Use of traditional biomass has a negative impact on human health and the environment. It is estimated that exposure to smoke from such households results in 4 million deaths annually globally due to household air pollution (HAP) related diseases, with millions more suffering from pneumonia, heart and lung diseases, blindness and burns [2]. Kenya records an average of 15,000 mortalities annually due to household air pollution related diseases [3]. Further, use of traditional biomass has a huge negative impact on women and girls in rural areas where this gender spend many hours a week gathering fuelwood, and for that, girls are not available for school while women have no time to engage in productive economic activities [4].

The Kenya forest sector contributes about Kenya Shillings 7 billion (USD 700 million) to the economy and employs over 50,000 people directly and with another 300,000 benefiting from the sector indirectly [5]. In addition, forest ecosystems enhance landscape resilience to climate change while the country's water-tower forests provide environmental services, which include: water quality and quantity, reduction of soil erosion, and creation of micro-climatic conditions that maintain or improve productivity as well; no-timber forest products such as honey, mushrooms, medicine and fodder as well as timber, poles and posts. Forests also play a big role in carbon sequestration; hence they are essential in contributing to climate change mitigation. In the past decade, Kenya's forests have been depleted at an alarming rate of about 5,000 hectares per annum [5]. The growing demand for fuelwood for both domestic and instruction use has been identified as one of the drivers for forest destruction [5].

$$
\mathrm{n}_{\mathrm{o}}=\frac{\mathrm{z}^{2} \mathrm{pq}}{\mathrm{e}^{2}}
$$

To address the energy crisis and its impact on the environment, since 1980s Kenya has been in the forefront in the development of improved cookstoves with initials names such as Kenya Ceramic Jiko (KCJ) becoming a household name in East Africa. The recent global effort to promote clean cooking solutions such as the establishment of Global Alliance for Clean Cookstoves (GACC) and United Nations Sustainable Energy for All Initiation (SEforAll) has further revitalized the move towards adoption of improved cookstoves. There are various definitions for improved cookstoves (ICS). For example, UNEP defines ICS as cooking stoves that use biomass (charcoal, wood, paper or vegetable matter) and are designed to maximize thermal and fuel efficiency, operate safely and minimize emissions harmful to human health [6]. In the context of this study improved cook stoves are used to refer to stoves that have better efficiency and reduced emission from the baseline stove (predominantly traditional three-stone cookstoves (TSC) and traditional metal charcoal stove without insulation).

Despite the three decades of improved cookstove development and promotion in Kenya, the penetration remains low especially in the rural areas where it is estimated that over $90 \%$ are still relying on the traditional three-stone cookstove (TSC) for cooking [1]. Lack of data on stoves testing has been proposed as one of the key bottlenecks to adoption of improved cookstove. Due to lack of data on stove efficiency, and with hundreds of claimed "improved cookstove stoves" in the market, the consumers are faced with a difficult task on deciding the right stove to buy. Many cases, such consumers end up buying cheap counterfeit or stoves with minimal improvement in terms of fuel efficiency. This scenario has made many consumers to lose faith in the stoves market. This study, therefore, aims to bridge this gap by providing data on stove performance of selected stoves in the Kenya market.

\section{Materials and Methods}

\subsection{Study Site and Approach}

The study was conducted in Kisumu County, Kenya between $3^{\text {rd }}$ and $15^{\text {th }}$ February 2020, covering all the seven sub-counties. It adopted a mixed method approach, which included quantitative and qualitative methods. Qualitative studies included literature review, key informant interviews (KIIs) and focused group discussion while quantitative studies included household interviews and stove performance-testing procedures.

\subsection{Household Survey}

Household interviews were conducted in all the 7 sub-counties of Kisumu. The interviews sought to assess the status of vegetation in the County and household energy. Sampling technique used involved random sampling, maximum variation/heterogeneous purposive sample and total population sampling methods for different target population. A maximum variation/heterogeneous purposive sample was selected to provide diverse range of key informants (based on the focus of this study). This ensured that key stakeholders and stakeholder groups (such as women, youth, men, civil society etc.) were included in the study. Within the different stakeholder groups, a list was generated from which random sampling was done to come up with the final samples. In selecting the sample size, we observed the following factors: (i) the estimated prevalence of the variable of interests (ii) the desired level of confidence and (iii) the acceptable margin of error. The sample size using the following standard Cochran formula:

Where:

$\mathrm{n}_{0}=$ minimum sample size required per study site in the target sub-counties

$\mathrm{Z}=$ statistically centrally chosen at 1.96 corresponding to $95 \%$ confidence level

$\mathrm{p}=$ the (estimated) proportion of the population which has 
the attribute in question,

$$
\mathrm{q}=(1-\mathrm{p})=0.2
$$

$\mathrm{e}=$ desired level of accuracy/level of precision at $5 \%(0.05)$

Using the above standard sample size calculation and considering the number of target households, a total of 400 , which included $10 \%$ for non-respondents samples were interviewed. The consultant team employed a multi-stage cluster sampling technique where the sub-counties were first-level clusters and $2^{\text {nd }}$ and $3^{\text {rd }}$ level clusters were the wards and sub-locations. Random sampling technique was used to select the houses for household interviews at sub-location level.

\subsection{Stove Performance Test}

Controlled Cooking Test (CCT) and Kitchen Performance Test (KPT) Protocols developed by Clean Cooking Alliance and partners were used for stove testing [7]. Fuel consumption estimates were collected for three full days, requiring daily household visits of four days. All fuels used within each household were weighed daily using Salter Brecknell (Fairmont, MN, USA) ElectroSamson digital hand-held scales (maximum $25 \mathrm{~kg}$; resolution $0.02 \mathrm{~kg}$ ). Wood moisture was measured daily in fuelwood using households with a digital HRPQ wood moisture meter (Osprey-Talon, USA). Three types of stoves were tested, which include TSC, Kuni mbili and Integrated Domestic Energy Unit (IDEU gasifier stove) (Figure 1). IDEU micro-gasifier stove) is also a forced draft. It comes with a charge controller along with one light and multi-plug mobile phone charging system. The system includes a solar panel that powers the battery fixed within the charge controller. Kuni Mbili is a natural draft wood powered stove. The name Kuni Mbili derived from Kiswahili words meaning "Two-Firewood". The stove is portable and is made from ceramic liner and a metal cladding over the liner. It is a modification of the three stone cookstove. A short survey was administered daily to record information about stove/fuel usage, the number and type of meals prepared, and the number of people for which the meals were prepared.
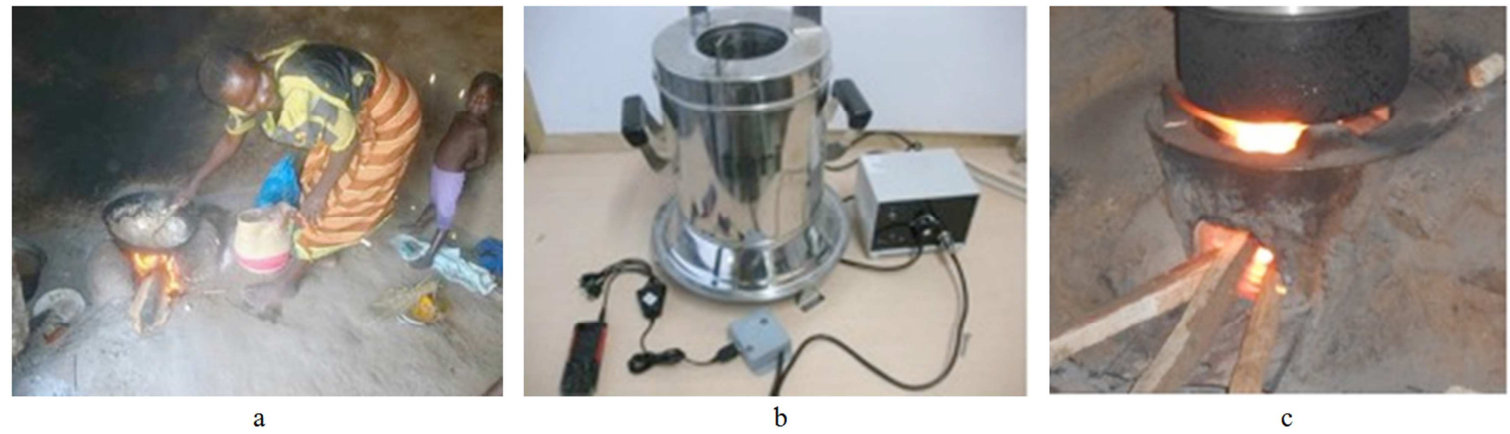

Figure 1. Cookstoves tested a) Kuni Mbili b) gasifier c) TSC.

\subsection{Limitations of the Study}

The study was limited in terms of arriving at the results, especially taking into account that not one type of fuel was used during the study. Various fuels have distinct caloric values hence affects the overall performance of the stove. Further, varying moisture content for the different biomass fuels used could have a significant effect on overall efficiency. For the case of forced draft, the heat in the combustion chamber has to first dry the fuel before combustion starts a factor that impairs the performance and sometimes ends up emitting smoke.

\section{Results and Discussion}

\subsection{Tree Cover}

The study sought to the status of forest in the County. In terms of tree planting, $83 \%$ of the respondents had planted trees in their farms. Kisumu Central had the highest number of respondents who have not planted trees (Figure 2). This could be explained to be because a large population of Kisumu Central residents are living in rental houses, thus do not have any obligation to plant trees. In many cultures planting a tree is seen as a claim of land ownership [8].

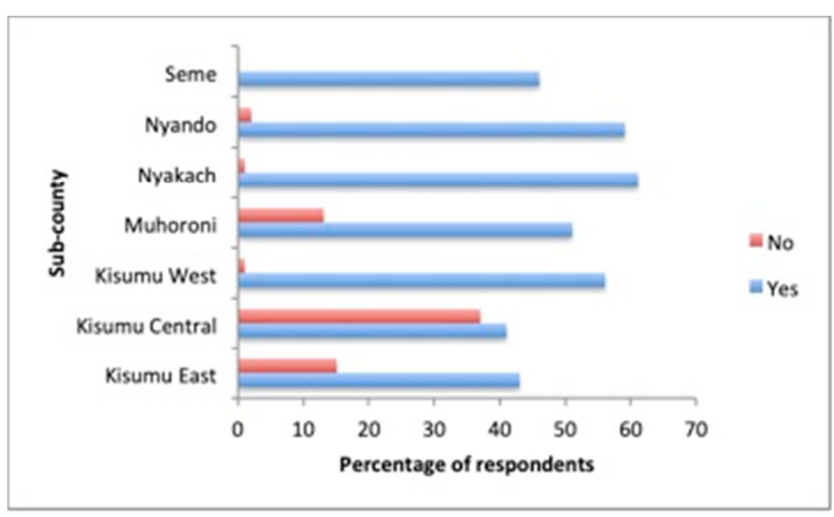

Figure 2. Tree planting.

Further, majority of the respondents believed that the tree cover in their areas is diminishing (Figure 3). Diminishing tree cover could have a big impact on the resilience of the community as well as the environment. Trees/forests are known to be one of the leading carbon sinks. Diminishing tree cover there means more carbon dioxide emission to the atmosphere. Further trees have essential roles in the ecosystem where they provide both products such as fuel, 
timber and poles and services such as soil fertility management, shade, among others. It is therefore a big concern that tree cover is diminishing in the County.

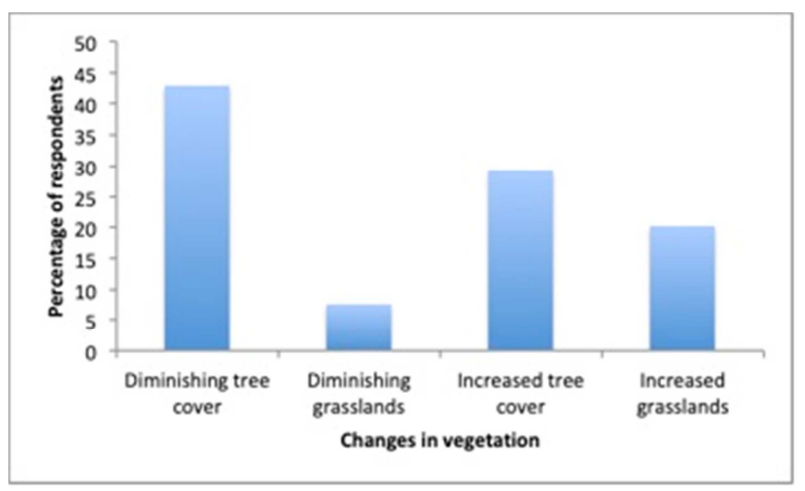

Figure 3. Change in tree cover

\subsection{Household Energy}

The study attempted to establish the status of household energy in the County. The data obtained shows that firewood and charcoal are the most dominant fuel used for cooking as recorded in $74 \%$ and $67 \%$ of the interviewed households, respectively (Figure 4). It is worth noting that there was pockets of people using briquette and biogas, which are some of the cleaner cooking solutions compared to firewood and charcoal, which are the traditional biomass systems.

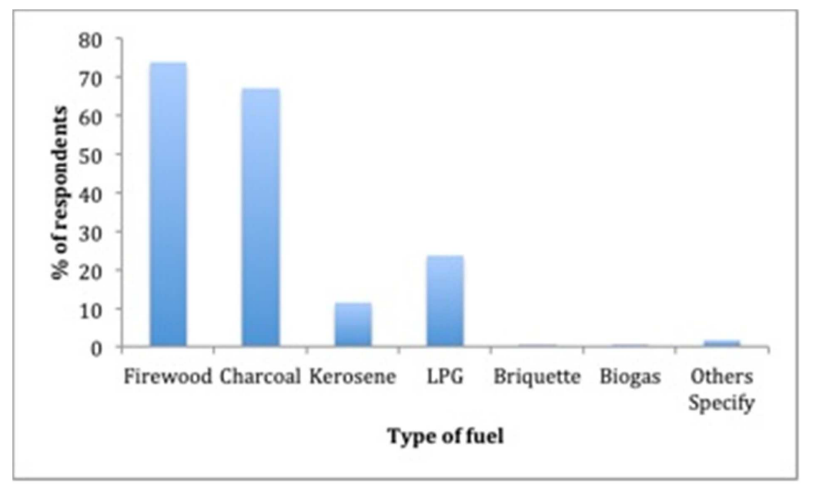

Figure 4. Types of fuel for household cooking

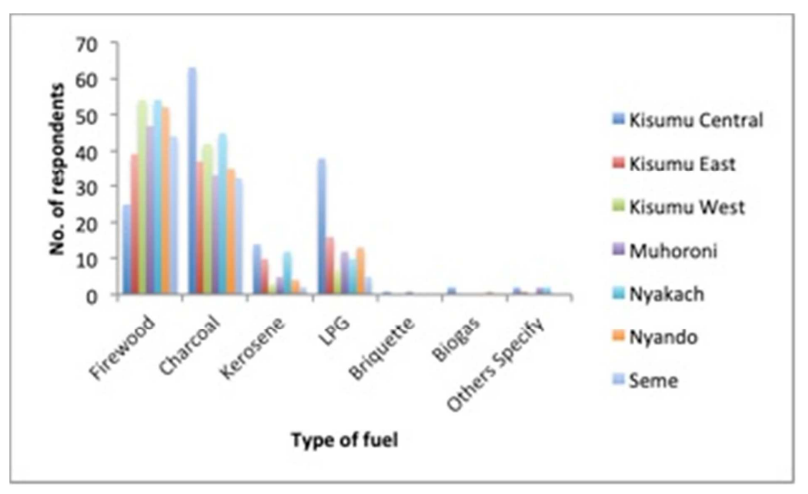

Figure 5. Type of fuel by sub-county

Comparison between the sub-counties shows that LPG is the leading fuel in Kisumu Central, while firewood and charcoal were the leading fuel in the other sub-counties. To put this into perspective, Kisumu Central primarily composed of Kisumu City and as expected in the cities, people tend to use liquefied petroleum gas (LPG) (Figure 5).

From the data collected, it was clear that in all the sub-counties, majority of the respondents are buying fuel (Figure 6). The highest numbers of households buying fuel were observed in Kisumu Central. Data collected further indicated that $75 \%$ of the population is facing fuel scarcity (data not showed).

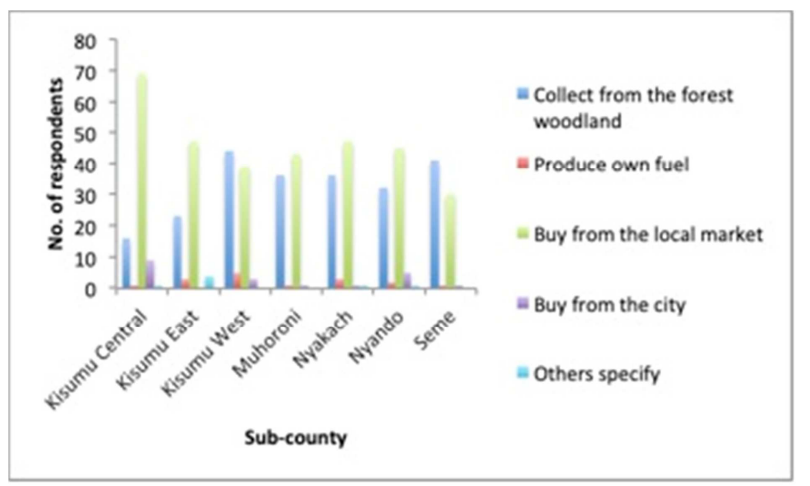

Figure 6. Source of fuel

The study also sought to understand the type of cookstoves used by the households. From the response received, traditional three-stone cook stove remains the dominant type of cookstove in the county as indicated by $73 \%$ of the respondents (Figure 7). This was followed by metallic cookstoves $(33 \%)$. Suffice to mention that these two are in the lowest tier of cookstoves standards according to the classification of cookstoves [9].

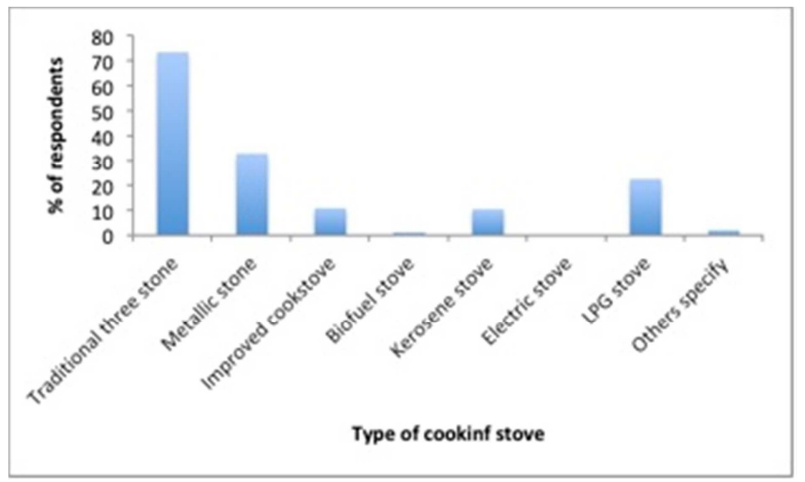

Figure 7. Types of stoves

\subsection{Stove Performance}

The study identified the cooking patterns and type of meals. Cooking patterns and the types of meals influence the amount of energy spent. During the morning (breakfast) period tea, and heating water feature predominantly. Most of the households usually did not cook heavy meals in the morning with $98 \%$ of the meals cooked comprising of meals that take less than an hour to complete (e.g. English tea). Lunchtime is relatively busy with some meals that require more time (ugali, vegetable, fish, green grams (ndengu), among others). However, cooks spend more 
time in the kitchen at night than day and are therefore likely to get exposed to IAPs for more extended periods.

A three-day KPT was conducted before and after the introduction of two intervention stoves, natural draft Kuni Mbili and a modified forced draft gasifier stove in the project area. As per the protocol, weights, moisture levels, and foods cooked were recorded. The data was processed using KPT protocol version 3.0. To adjust for differential energy needs across household sizes, a "Standard Adult" equivalence factor was used, which relates the fractional energy demand for cooking for a child, an elderly person to that of an adult man of reproductive age. Table 1 shows the standardized adult equivalents used in KPT calculation template 3.0.

Table 1. Standard Adult Equivalents.

\begin{tabular}{ll}
\hline Gender and age & Fraction of Standard Adult \\
\hline Child: 0 -14 years & 0.5 \\
Female: over 14 years & 0.8 \\
Male: $15-59$ years & 1 \\
Male: over 59 years & 0.8 \\
\hline
\end{tabular}

"Standard Adult" equivalence factors defined in terms of sex and age [10].

The adult equivalent conversions per household per stove showed the same number of people were cooked for throughout the KPT period. To provide a more realistic comparison that allow for the different use patterns between the stoves, the fuel consumption estimates were calculated on a total energy content rather than the weight of fuel used during KPT by each stove. Values for the energy conversion were taken from the KPT protocol. Table 2 gives a summary of fuel and energy consumption per household by stove type. It indicates the amount of fuel used per day, fuel and energy use per capita. Fuel use per capita ( $\mathrm{Kg} /$ Standard Adult) indicates the amount of fuel used per Standard Adult (SA) irrespective of whether they are adults (male or female) or children. Energy per capita (MJ/SA) takes into consideration the adult equivalents in calculations and is the better way to compare stove savings without bias.

Table 2. Summary of daily fuel and energy use in the households per stove.

\begin{tabular}{lllll}
\hline \multirow{2}{*}{ Stove type } & \multirow{2}{*}{ Daily fuel use (Kg)/HH/Day } & \multirow{2}{*}{ Fuel use per capita (kg/SA/Day) } & \multicolumn{2}{c}{ Energy per capita (MJ/SA)/Day } \\
\cline { 4 - 5 } & & & Firewood & 28.03 \\
TSC & 6.23 & 2.94 & 23.67 & 30.13 \\
Kuni mbili & 4.17 & 2.77 & 19.79 & 28.56 \\
Gasifier & 3.55 & 2.52 & 22.82 \\
\hline
\end{tabular}

When we consider daily fuel use per household per day shown in table 3 , there was some reduction in the amount of firewood used by a household per day from $6.23 \mathrm{~kg}$ /day for TSC, $4.17 \mathrm{~kg} /$ day and $3.55 \mathrm{~kg} /$ day for Kuni mbili and Gasifier respectively. The variability in fuel consumption is functions of the cooking systems, which vary in cooking demands, tending practices, thermal efficiencies, and other factors, which accounts for the differences in the three households. However, fuel used per day does not take into consideration of the adult equivalent, and wood characteristics, such as moisture content have not been taken into consideration.

Fuel use per capita and energy per capita are better indicators of fuel savings made by using the different kinds of stoves. Gasifier performer better in the fuel use per capita with $2.52 \mathrm{~kg} / \mathrm{SA} /$ day) followed by Kuni mbili and TSC with $2.77 \mathrm{~kg} / \mathrm{SA} /$ day and $2.94 \mathrm{~kg} / \mathrm{SA} /$ day respectively.

In order to assess the overall performance of each stove irrespective of household size and to provide a more realistic comparison that allows for the different use patterns between the stoves, the fuel consumption estimates were calculated on a total energy rather than weight. Values for the energy conversion were taken from the KPT protocols. Therefore, energy per capita expressed in mega joules per standard adult $(\mathrm{MJ} / \mathrm{SA})$ is the most superior method of determining stove's efficiency since it takes into consideration not only the adult equivalent but also wood moistures levels which affects the calorific values of the fuel.

The Gasifier had the best (least) energy per capita of 19.79MJ/SA/day, followed by Kuni Mbili (23.67MJ/SA/day) and finally TSC with $28.03 \mathrm{MJ} / \mathrm{SA} /$ day taking into consideration that firewood is the primary fuel. In the total energy per capita which includes firewood and charcoal which was the primary fuels used in the houses; the Gasifier still outperforms the other stoves as shown on the last column that showed a reduction of $29 \%$.

Table 3 presents a comparison between the stoves. A positive percentage gives the percentage improvement with diminishing improvement indicated by negative percentages. Calculations were done using the stove type that was considered to be less improved as the baseline or traditional being, which was used as the baseline of improvement. In the case of TSC vs. Kuni Mbili and TSC vs. Gasifier, the traditional TSC was used as the basis for comparison while Kuni Mbili was used as the comparison base in the case between Kuni Mbili versus Gasifier. The general formula was:

$\underline{\text { (less improved stove }- \text { Improved stove) } \times 100}$ (less improved stove)

Table 3. Comparison of Stove's daily fuel use and energy per capita.

\begin{tabular}{llllll}
\hline \multirow{2}{*}{ Stove type } & \multirow{2}{*}{ Daily fuel use (Kg)/HH/Day } & Fuel use per capita (kg/SA/Day) & \multicolumn{2}{c}{ Energy per capita (MJ/SA)/Day } & Firewood \\
\hline TSC & & & $16 \%$ & Total fuel (Firewood \& charcoal) \\
Kuni mbili & $43 \%$ & $14 \%$ & $29 \%$ & $24 \%$ \\
Gasifier & $15 \%$ & $9 \%$ & $16 \%$ & $20 \%$ \\
\hline
\end{tabular}


In the comparison of TSC versus Kuni Mbili, the superiority of Kuni Mbili over TSC was visible with a $6 \%$ improvement in fuel use per capita $16 \%$ improvement in firewood energy per capita and 5\% total energy per capita (total considering other fuels in use). This is expected since Kuni Mbili stove has insulation and therefore requires less fuel to perform cooking tasks compared to three-stone fire. In TSC versus Gasifier, there was an even higher improvement with fuel use per capita recording an improvement of up to $29 \%$ and $24 \%$ in firewood and total energy use, respectively (Table 3). This finding illustrates the superiority of the forced draft gasifier-intervention firewood stove over the baseline stoves. Similar improvement was recorded on the comparison of Kuni Mbili versus Gasifier, albeit at a lower percentage.

Felling of forest for woodfuel (charcoal and firewood) is among the main drivers of forest destruction in Kenya together with illegal logging of indigenous trees, illegal squatters, the changing lifestyle of forest-dwelling communities, unclear forest zonation, the introduction of irregular settlements and expansion of agricultural land [11]. These changes are taking place forest governance takes place amidst political devolution, changing natural resource policies and laws, and environmental change [12]. Approximately 200-300 trees are needed per household per year [13]. Therefore destruction of the natural woodland and forest for wood fuel is a national concern, and therefore adoption of improved cookstoves (ICS) could play a big role in addressing the problem [14].

With its potential to contribute to energy saving and reduce forest destruction, ICS, therefore, has become an essential sector in Kenya. In a recent study, Kenya Climate Change Innovation Centre (KCIC) indicated that Kenya has a mature ICS sector coupled with an inherent desire for the adoption of modern technologies [15].

\section{Conclusion}

The study has provided valuable data on kitchen performance which provides insight into the potential energy saving as well as and savings in the forest cut by adopting improved cookstove for household cooking. Besides, the study also pointed out the weaknesses of some of the improved stoves in the market and the need for further design adjustment to improve efficiency and minimize household air pollution. The study elucidates that while is substantial saving energy in using improved cookstoves, there is a huge disparity between different improved cookstoves in the market. For the households to fully benefit from improved cookstoves, there should be an effective system of quality control.

This study was conducted on very limited types on the stoves taking in to account the fact that there are hundreds of types of stoves in the Kenya market today. This calls for more research and monitoring of stove efficiency and possibly establishment voluntary testing and accreditation centres to ensure the market is getting quality stoves that can meet the intended outcomes. Further, there is a need for awareness creation among the users to be able to select stoves based on their efficiency.

\section{Acknowledgements}

The study was supported by the National Research Fund, Kenya for the Market Based Diffusion of Cookstoves in Kenya Project awarded to the senior author. We thank the Energy Resource Institute, Delhi, India, for donating the Integrated Domestic Energy Unit (IDEU micro-gasifier stove) used in this study. Last but not list, we are highly indebted to all the respondents who gave valuable information during this study.

\section{References}

[1] GoK, CCAK, "Kenya Household Cooking Sector Study: Assessment of the Supply and Demand of Cooking Solutions at the Household Level," 2029.

[2] F. Lambe, M. Ju risoo, M., C. Lee, C. et al. "Can carbon finance transform household energy markets? A review of cookstove projects and programs in Kenya" Energy Research \& Social Science, 5, 55-66. 2015 https://doi.org/10.1016/j.erss.2014.12.012.

[3] BO Muok, "Developing an Innovative and Sustainable Market-Based Systems for Enhancing Diffusion of Clean Cooking Solutions in Kenya" International Journal of Science. Vol. 7. pp. 57-67. 2018, DOI: 10.18483/ijSci.1716.

[4] T. Urmee, S. Gyamfi, S. A review of improved Cookstove technologies and programs. Renewable and Sustainable Energy Reviews 33 (2014) 625-635. 2014.

[5] Ministry of Environment and Forestry (ME\&F). Taskforce Report on Forest Resources Management and Logging Activities in Kenya. 2018 pp. 130.

[6] UNEP, "Investing in improved stoves in Haiti", Discussion paper, July 2010. United Nations Environment Program, 2010.

[7] https://www.cleancookingalliance.org/technology-and-fuels/te sting/protocols.html.

[8] Mugure, A., PG Oino BM Sorre, "Land Ownership and its Impact on Adoption of Agroforestry Practices among Rural Households in Kenya: A Case of Busia County". International Journal of Innovation and Applied Studies Vol. 4 No. 3, 2013 pp. 552-559.

[9] GACC (Global Alliance for Clean Cookstoves) and ESMAP (Energy Sector Management Assistance Program) (2013). ESMAP Upcoming Report: State of the Global Clean and Improved Cooking Energy Sector 2013. ESMAP, World Bank, Washington, DC.

[10] K. Openshaw "Guidelines for Wood fuel Surveys" FAO 2002.

[11] E. Nkonya, A. Mirzabaev, J. von Braun (eds), Economics of Land Degradation and Improvement - "A Global Assessment for Sustainable Development." Springer Cham Heidelberg New York Dordrecht London. 2016. pp 116. 
[12] BO Muok, SH Eriksen, M Mosberg, DO Ong'ech, Forest governance in the face of climate change and political devolution: The case of Mukogodo Forest, Laikipia County, Kenya (in preparation un published).

[13] Ogweno D. O., Opanga P. S. and Obara A. O. (eds). Forest Landscape and Kenya's Vision 2030. Proceedings of the 3rd Annual Forestry Society of Kenya (FSK) Conference and
Annual General Meeting held at the Sunset Hotel, Kisumu. 30th September - 3rd October, 2008, pp 185.

[14] ESMAP \& GACC, The State of the Global Clean and Improved Cooking Sector. Technical Report July 2015.

[15] KCIC, Sector mapping and market assessment on the improved cookstoves (ICS) sector in Kenya, 2017. pp 55. 